\title{
FURTHER EVIDENCE REGARDING THE SPINAL CORD PARALYSES FOLLOWING SPINAL ANESTHESIA
}

\author{
Foster Kennedy
}

Abraham S. EFfron

Doctor Foster Kennedy is deeply sorry that he could not be here to address you on the subject of spinal cord paralyses following spinal anesthesia. This subject is very close to his mind and deep to his conseience. Only the most definite opinions of his physicians, who forbid him to make the journey, could persuade him against presenting such a serious problem to this fine audience, and especially to the surgeons, obstetricians and anesthetists who may be present.

During the past 5 years, detailed accounts of various types of spastic spinal paralyses brought on by the use of spinal anesthesia were published by Doctor Kennedy and his colleagues ${ }^{1,2}$ at Bellevue Hospital. It is important at the outset to note that these sequelae of surgical and obstetrical procedures are not generally observed while the patient is in hospital, but are usually seen independently by the neurologist weeks or months after the patient has been discharged from hospital. The early complaints include numbness, weakness of feet and legs, sphincter loss and sensory loss often over periods of months. In the majority of cases symptoms are mild immediately after spinal anesthesia, and only proceed to a paralytic stage weeks or months later. Thus, the surgeons and anesthetists employing spinal anesthesia do not become aware of the grave results often emerging from their procedures.

For a period of a few weeks after the publication of our article about the grave spinal cord paralyses caused by spinal anesthesia in October $1950^{2}$, we received 70 letters from people who became paralyzed follow-

From the Neurological Service of Bellevue Hospital, New York, U.S.A.

Nota da Redação - Éste trabalho, o último escrito pelo Dr. Foster Kennedy e preparado para uma apresentação perante congresso médico, foi enviado ao Dr. L. Barraquer-Bordas pela viúva daquele pranteado neurologista, acompanhado das seguintes palavras que emprestam grande valor à sua publicação nesta revista: "As you probably know by now my dear husband, Foster Kennedy, was called away from us on the 7th of January of this year. In going through: the correspondence which he had to leave unanswered, I found a letter from you asking that he should submit an original paper for the June issue of the Arreivos DE Neuro-Pssiquiatria which is to be published in honour of your father. I am taking the liberty of enclosing the last paper which my husband wrote, which has not yet been published in this country. I should be very bappy if you would use this article for my husband greatly respected your father". 
ing spinal anesthesia. All of them had been assured the operation or anesthetic was blameless. Some sought help and relief from their affliction, and others were hopeful as one patient who wrote, "Perhaps now it won't happen to others".

Many of these patients presented early symptoms which were most often thought to be due to "post-operative weakness", and in the present. general poverty of neurological knowledge, the subsequent paralysis in many of our 70 paralyzed people was calied "multiple sclerosis", while in a smaller number they were referred to as "psychosomatic" complaints. These diagnostic errors and the lack of subsequent examinations once a post-operative patient has been discharged are responsible for the diversity of statistics which exist in medical literature concerning the complications of spinal anesthesia.

We are told in those cases where serious neurological complications followed spinal anesthesia, the etiological factor was not the spinal anesthetic but resulted from "previously undiagnosed neurological disease". However, if the anesthetists and surgeons who put forth this theory really believe it to be so, why do not all pre-operative patients have a careful and complete neurological examination? Do they soothe their consciences by believing that the patient was not paralyzed by their procedure, but that it would have happened anyhow? We do not deny that an occasional case may have pre-existing disease of the central nervous system. Yet, in spite of this, the use of spinal anesthesia has come to be so routine a procedure for some men that the administration of this type of anesthetic is not withheld even for such a case. If this so-called pre-existing disease of the central nervous system is latent and cannot be determined even after examination, are we right to take the risk of introducing an anesthetic agent into the intrathecal space? This is not even a calculated risk, for we have no means of testing the patient and weighing the risk.

We will briefly review some of the facts from the literature as previously reported by us, and then add additional clinical and pathological evidence. Animal experiments by independent investigators have resulted in agreement that the anesthetic substance is the etiological agent responsible for central nervous system complications produced by spinal anesthesia. The damage is " "located in the spinal cord, most marked near the site of injection; the nerve roots and spinal ganglia are commonly spared". "There are: 1) constant but varying degrees of meningeal reaction with cellular proliferation and infiltration which may progress to cicatrization; 2) changes in the ganglion cells of the grey matter with swelling, rounding, chromatolysis, achromatosis and disappearance of cell fibrils; 3) swelling and fragmentation of the axis cylinders of the nerve roots, especially in the posterior and lateral columns together with degenerative changes in the fiber tracts of the spinal cord, most marked below the lower dorsal segments of the cord; 4) peripheral degeneration of the myelin sheath of the spinal cord". 
These are essentially the same pathological changes seen at operation or post-mortem in patients who have had complications after spinal anesthesia. The lesion of chronic progressive arachnoiditis compressing the spinal cord has been verified by both touch and vision. In none of our cases has there been any improvement as a result of operation. In most cases a manometric spinal fluid block occurred, and all of those reported had sustained severe pyramidal tract lesions, most times accompanied by a sensory spinal level below which sensation is either lost or inadequate, together with paralyzing of sphincters and, in men, loss of potency. The progressive paralysis is due, of course, to the progressive tightening of arachnoid adhesions around the spinal cord.

D. M.*, a 19 year old woman, had an uneventful period of pregnancy. She received a saddle block anesthesia with $5 \mathrm{mg}$ of nupercaine at the level of the third lumbar interspace. Shortly thereafter a sensory level could be demonstrated at the 7th thoracic segment. 'Iwo hours later the patient went into vasomotor collapse, with a respiratory rate of 5-6 per minute. Lumbar puncture four hours after the administration of the anesthetic agent revealed clear cerebrospinal fluid with a pressure of $140 \mathrm{~mm}$. of water. On examination the next day, she was in coma. The lower limbs were paralysed and flaccid. The spinal fluid pressure was $470 \mathrm{~mm}$. of water and the fluid contained 3114 R.B.C. and 741 W.B.C. of which $81 \%$ were polymorphs. The patient's condition remained essentially unchanged, except for the demarcation of a sensory level at the 5 t: 1 thoracic spinal segment on the left, and 2nd thoracic spinal segment on the right. On the 19th day repeated attempts at lumbar puncture were unsuccessful. A ventriculogram the next day showed a symmetrical dilation of the ventricles, with an especial dilation of the 4th ventricle. 'These air studies were interpreted as indicating the presence of internal hydrocephalus, and a shunting operation to relieve the obstructed ventricles was decided upon. A left ventriculomastoidostomy was performed, without remedy. Our clinical diagnosis was meningo-myeloencephalitis secondary to the spinal anesthesia. The patient died on the 86 th day after the anesthetic had been administered.

A description of the spinal cord at post-mortem reads as follows: "Ihe dural envelope is not readily removed; in extensive regions there is obliteration of the subdural space with fibrous adhesions. These adhesions are separated with considerable difficulty. The spinal cord then presents an arachnoidal surface which is of diminished lustre and shows splotchy yellow and brown discolorations, this change being most marked in the thoracic region. There is obvious thickening of the arachnoid. Cross sections of the lower cervical spinal cord reveal normal landmarks. However, in cross sections through the thoracic cord, the markings are seen to be completely obscured and the substance of the cord is generally peculiarly yellow and opaque in these regions; in certain sites, brown discoloration is noted; in other areas, the cord appears as though honey-combed with small cavities. In the region of the arachnoid cisterns, the arachnoid is thickened and of diminished transparency; adhesions of arachnoid to pia are encountered, this change being most marked in the region of the cisterna magna. The arteries at the base of the brain are embedded in thickened arachnoid membrane. The dominant pathological process is a severe chronic reactive leptomeningitis throughout the spinal cord and brain stem. The destructive changes

* Personal communication from Drs. A. S. Effron, Juan Fonseca and $H$. S. Khu. Pathology of this case: examination and report by Dr. Webb Haymaker (Armed Forces Institute of Pathology). 
in the cord and brain stem are of a non-inflammatory nature and are regarded as the result of progressive ischemic necrosis. The distribution of the necrotic lesions in the brain stem are directly related to the arteries affected".

An abstract from the pathological report of one of our earlier cases reads: "The spinal cord grossly was reduced to a ribbon-like structure". Microscopic examination disclosed widespread and marked alterations in the nature of a diffuse and, in places, of a patchy demyelinating and rarifying process. In the opinion of the neuropathologist, the disease process was a "degenerative disintegrating disease due predominantly to some toxic agent".

In addition, we can relate the neurological sequelae of two young women patients who received saddle block anesthesia during labor. One began to complain of numbness of her legs five weeks post-partum, and several weeks later presented a clinical picture of complete transverse myelitis at the level of $D_{r}$. The second patient was asymptomatic until 9 months after delivery. In both patients there was a complete subarachnoid block. On laminectomy they showed a typical adherent arachnoiditis with a very sharp demarcation between the involved and the normal portion of the cord.

We would also like to comment on a patient who complained of lack of sensation in the feet some months after a caesarian operation under spinal anesthesia. This sensory loss was slowly progressive over a period of months. No spinal fluid could be obtained with repeated lumbar puncture. Myelogram revealed marked arachnoidal thickening. The patient became pregnant again during the next year. During this pregnancy her condition was noted to improve remarkably. The vascular changes occasioned by the second pregnancy, as far as we can determine, could not have been sufficiently definite to be the agent responsible for the recovery from the existing arachnoiditis. 'Therefore, we suggest that it might be of interest in cases of post-spinal arachuoiditis to attempt to dissolve the arachncidal adhesions by reproducing the hormone conditions found in pregnancy. Since the adrenal cortex experiences great stimulation during pregnancy, the use of $\mathrm{ACl}$ 'H and Cortisone might well be experimentally evaluated.

\section{COMMENT}

"The neurological complications of spinal anesthesia occur in those regions of the central nervous system or its membranes most closely situated to the site of injection of the anesthetic compound. This is attested by the reported cases, together with operative and post-operative observation. These sequelae are rarely due to direct injury since such accidents are not found after lumbar puncture. In rare cases, marked symptoms occur in patients who complain of severe pain during the injection of the anesthetic". On introduction of the effective agent into the subarachnoid space dilution and diffusion occur, but not before considerable absorption and fixation have taken place near the site of injection where the membranes and nerves are in contact with the full concentration of the anesthetic drug" 2 .

The anesthetic drug is the toxic agent in these cases. MacDonald and Watkins ${ }^{3}$ have shown the concentration of the necessary annectant chemical substance in the anesthetic solution other than the anesthetic drug canno: produce paralysis. It has been suggested from time to time that a con- 
tributory cause may be the possibility of alcohol or other sterilizing fluid seeping into the anesthetic vials either by defective sealing or minute breaks, or perhaps by bacterial contamination. If this should prove true, then certainly the only way to avoid this complication is by the administration of other methods of anesthesia rather than spinal.

We are then asked whether general anesthesid is any "safer" than spinal anesthesia. It is not easy to obtain reliable figures on this subject because of the frequent time lag in insiduous paralysis. It is cur impression that the lethal statistics as regards spinal and general anesthetics are about the same, but that spinal paralyses occur sufficiently often after spinal anethesia to become highly noticeable in neurological wards of a general hospital. Those cases in which the spinal anethesia has been unsuccessful and has to be followed by volatile anesthesia should not be too lightly forgotten. There is no such thing as conservative choice of spinal anethesia because we cannot know beforehand whether the patient will become one of the paralyzed. Certainly paralysis of the lower limbs, and a tied-in catheter should not be a possible complication of a simple herniotomy, appendectomy, or a delivery. From the neuiological point of view, we repeat the opinion that spinal anesthesia should be rigidly reserved for those patients unable to accept a local or general anesthetic. One of the most distinguished surgeons in the country informs us that he has given up spinal anesthesia since these paralyses cases were published and "that morning he had done two sigmoidectomies under perfect operative conditions with pentothal and curare". Anesthetists and obstetricians should not employ this method of anethesia if any other be available. To do so shows a lack of reverence for tissue; spastic paraplegia is altogether too high a price to ask a patient to pay in order that the anesthetist should have a simple anesthetic administration, and the surgeon a clear field of relaxation in which to employ his skill.

\section{BIBLIOGRAPHY}

1. Kennedy, F., Somberg, H. M. and Goldberg, B. R. - Arachnoiditis and paralysis following spinal anesthesia. J.A.M.A., 129:664, 1945.

2. Kennedy, F., Effron, A. S. and Perry, G. - The grave spinal cord paralyses caused by spinal anesthesia. Surg., Gynec. a. Obst., 91:1, 1950.

3. MacDonald, A. C. and Watkins, K. H. - An experimental investigation into the cause of paralysis following spinal anesthesia. Brit. J. Surg., 25:879, 1937-1938. 